\title{
Cana de açúcar na alimentação de novilhas leiteiras: Revisão
}

\author{
Graciele Araújo de Oliveira Caetano ${ }^{1 *}$, Messias Batista Caetano Júnior², Maryelle \\ Durães de Oliveira ${ }^{3}$, Leandro Munhoz Socreppa ${ }^{3}$
}

${ }^{1}$ Mestre em Produção Animal, UFVJM. Estudante especial do Doutorado em Produção de Ruminantes. Universidade Federal de Goiás (UFG-EVZ), Goiânia-Goiás, Brasil.E-mail: gracielecaetano@outlook.com

${ }^{2}$ Zootecnista, Instituto Federal de Minas Gerais (IFMG), Bambuí- Minas Gerais, Brasil. E-mail: caetanozootecnia@hotmail.com, mary_zoo@hotmail.com

${ }^{3}$ Doutorando em Zootecnia. Universidade Federal de Goiás (UFG - EVZ), Goiânia-Goiás, Brasil. E-mail: leandroms@zootecnista.com.br

*Autor para correspondência

\begin{abstract}
RESUMO. A presente revisão de literatura tem como objetivo apresentar como a cana de açúcar é utilizada na recria de novilhas leiteiras. Algumas características relacionadas à cultura da cana de açúcar, tais como a facilidade de seu cultivo, a execução da colheita justamente na época de estiagem, possibilidade de auto armazenamento ou conservação a campo, persistência da cultura e a grande produção obtida em nossas condições tornaramna um alimento de grande interesse dos criadores. Fêmeas em recria necessitam de um ganho de peso que garanta uma idade ao primeiro parto aos vinte e quarto meses de idade. Serão relatados os sistemas de recria de novilhas, os aspectos importantes ligados à nutrição de novilhas, limitações do uso da cana de açúcar para bovinos, composição e a produtividade da cana de açúcar. Os resultados de diferentes trabalhos de pesquisa sugerem várias formas de utilização da cana de açúcar para a obtenção de resultados satisfatórios como a cana in natura, cana com ureia, a silagem de cana, cana hidrolisada e o bagaço da cana de açúcar. Apesar da baixa digestibilidade da cana de açúcar e do menor ganho de peso das novilhas quando comparadas com outros tipos de alimentações como, por exemplo, a silagem de milho, a cana de açúcar mostrou-se ser uma alternativa viável para recria de novilhas leiteiras em propriedades pouco tecnificadas.
\end{abstract}

Palavras chave: Bovinos leiteiros, novilhas, formas de utilização de cana de açúcar

\section{Sugar cane in feeding of milker heifers: Review}

\begin{abstract}
This review aims to present how sugarcane is used in the rearing of dairy heifers. Some characteristics related about the culture of sugarcane, such as ease of cultivation, implementation of crop in the dry season, the possibility of self-storage or conservation field, persistence of culture and great production obtained in Brazilian conditions They made it a food of great interest to breeders. Females in growing need an average weight gain that guarantees an age at first calving at twenty-four months old. Will be reported the dairy heifer's systems, important aspects of heifers' nutrition, limitations of use of sugarcane for cattle, composition and productivity of sugarcane. The results of different research papers suggest several ways of using sugarcane to obtain satisfactory results as in natural cane, cane with urea, silage cane, hydrolyzed cane and bagasse from sugarcane. Despite the low digestibility of sugarcane and less weight gain for heifers as compared to other feeds, for example, silage corn, sugarcane proved to be a viable alternative for rearing dairy heifers little technicality properties.
\end{abstract}

Keywords: Dairy cattle, heifers, ways of using sugarcane

\section{Introdução}

O Brasil é o maior produtor mundial de cana de açúcar, a qual se destaca entre as gramíneas

tropicais como a planta de maior potencial para produção de matéria seca e energia por unidade 
de área, em um único corte por ano (Abreu, 2012). Justifica-se a utilização da cana de açúcar como recurso forrageiro pela facilidade de cultivo, baixo custo por unidade de matéria seca produzida e a maturidade coincidindo com o período seco do ano, dadas algumas limitações citadas por Costa et al. (2005).

A recria de novilhas leiteiras no Brasil, sob o ponto de vista dos produtores encarece o sistema de produção de leite, já que estes animais são improdutivos até chegarem à primeira parição. Segundo Weber et al. (2002) apud Teixeira et al. (2007) essa visão entre os criadores de gado de leite aumenta o período de recria até o primeiro parto e o número de novilhas nas fazendas, diminuindo o potencial de produção. Assim, é importante determinar ganho de peso satisfatório para obtenção de desenvolvimento ideal desses animais e redução da idade ao primeiro parto.

Teixeira et al. (2007) acreditam que, dessa forma e notória a necessidade de investimentos em alimentação, o que contraria os objetivos de proprietários que destinam o maior investimento em alimentação as vacas que estão produzindo leite. Amaral Neto et al. (2000) apud Pinto et al. (2003) afirmam também que isto tem estimulado os pesquisadores a estudarem as diferentes alternativas alimentares que supram esses problemas e minimizem o custo da alimentação, principalmente no período de entressafra em que existe escassez de forragens com a consequente falta de volumosos adequados em quantidade e qualidade, afetando o sistema de produção animal. De acordo com França et al. (2005) uma das principais estratégias para o aumento da eficiência para pecuaristas e a utilização de plantas adequadas aos períodos críticos de produção de forragem. Algumas características relacionadas à cultura da cana de açúcar, tais como a facilidade de seu cultivo, a execução da colheita justamente na época de estiagem, possibilidade de auto armazenamento ou conservação a campo, persistência da cultura e a grande produção obtida em nossas condições tornaram-na um alimento de grande interesse dos criadores (Rodrigues et al., 1997).

A presente revisão de literatura objetiva discutir o uso de cana de açúcar (Saccharum officinarum L.), relatar os sistemas de criação utilizados, mostrar as exigências nutricionais e avaliar as formas de utilização de cana de açúcar na recria de novilhas leiteiras.

\section{Tipos de sistemas de recria de novilhas}

\section{Recria a pasto}

Ribeiro et al. (2005), em seu experimento, avaliaram o consumo e o ganho de peso de novilhas leiteiras de reposição em sistema de pastejo rotacionado de Brachiaria brizantha cv. Marandu, durante os meses de marco, abril e maio de 2001. Os tratamentos consistiram de animais exclusivamente em pastagem de B. brizantha e de animais em pastagem de B. brizantha recebendo suplemento com 40 e $60 \%$ de proteína não-degradável no rúmen (PNDR). Os consumos de MS (matéria seca) e de proteína bruta $(\mathrm{PB})$ praticados pelas novilhas em recria exclusivamente a pasto decresceram à medida que se aproximava a estação seca propriamente dita, com valores médios observados de 153 e 95 $\mathrm{g} / \mathrm{kg}$ de PV-0,75/dia, para MS, e 25 e $7 \mathrm{~g} / \mathrm{kg}$ de PV-0,75/dia, para PB, respectivamente, nos meses de marco e maio. Quanto ao consumo de Fibra em Detergente Neutro (FDN), observou-se substancial redução do primeiro período para os períodos subsequentes. Em contrapartida, a ingestão de Fibra em Detergente Neutro Indigerível (FDNI) ajustada elevou de 7 para 10 $\mathrm{g} / \mathrm{kg}$ de $\mathrm{PV}-0,9 /$ dia $(\mathrm{P} \leq 0,05)$ de marco para maio. $\mathrm{O}$ nível de adição de $\mathrm{PNDR}$ influenciou $(\mathrm{P} \leq 0,05)$ o consumo de proteína bruta $(\mathrm{CPB})$ da forragem e da ração total. Foi observado que a adição de suplemento proporcionou os efeitos complementares aditivo, expresso pelo ganho de peso, e substitutivo, caracterizado pela redução do consumo de matéria seca da forragem, com concomitante aumento no consumo de matéria seca da ração total. O ganho de peso não foi influenciado pela adição de suplemento com níveis de 40 e $60 \%$ de PNDR, quando comparados entre si e com o ganho exclusivamente em pastagem.

Segundo Prado et al. (2003) pastos de excelente qualidade e bem manejados podem suprir os nutrientes para o crescimento das novilhas, desde que uma mistura mineral esteja sempre à disposição. A suplementação volumosa na época seca deve e pode ser feita com forragens verdes picadas, cana de açúcar adicionada com $1 \%$ de ureia, silagens ou fenos.

\section{Recria em Sistema Silvipastoril}

Aroeira et al. (2004) avaliaram a massa de forragem e o ganho de peso de novilhas leiteiras mestiças, de peso vivo inicial médio de $250 \mathrm{~kg}$, mantidas no SSP (Sistema Silvipastoril) e na 
monocultura de Brachiaria decumbens. Observaram que valores de massa de forragem e taxas de lotação no SSP e na monocultura de B. decumbens não diferiram entre si, o que resultou em ganhos de peso para novilha por hectare semelhantes. Durante o período seco, o ganho de peso por novilha foi maior no SSP com Sthilosantes guianensis (326 g/animal/dia), em relação ao observado na monocultura de $B$. decumbens (236 g/animal/dia) e no SSP sem $S$. guianensis (145 g/animal/dia).

Segundo Alvim et al. (2005) a recria de novilhas leiteiras em pastagens arborizadas tem se mostrado viável tecnicamente. $\mathrm{O}$ quadro 1 mostra a taxa de lotação e os ganhos de peso de novilhas leiteiras mantidas em pastagem exclusiva de Brachiaria decumbens e na pastagem arborizada (modelo de sistema silvipastoril). Observa-se que, a taxa de lotação na pastagem arborizada foi mais elevada do que a da pastagem de Brachiaria decumbens e que, no geral, o ganho de peso foi elevado nas duas condições e ao longo de todo o ano, mas os animais da pastagem arborizada tiveram maior ganho de peso, principalmente na época da seca, provavelmente devido à diversidade e melhor qualidade da forragem.

Alvim et al. (2005) afirmam que uma mistura mineral deve estar sempre à disposição dos animais, como afirmaram.

Quadro 1. Taxa de lotação (novilhas/ha) e ganho de peso vivo (g/animal/dia e kg/animal/ano)de novilhas leiteiras em pastagem arborizada e em pastagem exclusiva de B. decumbens.

\begin{tabular}{|c|c|c|c|c|c|}
\hline \multirow{3}{*}{ Tratamentos } & \multicolumn{3}{|c|}{ Ganho de peso $^{1}$} & \multirow{2}{*}{\multicolumn{2}{|c|}{$\begin{array}{c}\text { Taxa de lotação } \\
\text { Novilhas/ha }\end{array}$}} \\
\hline & \multicolumn{2}{|c|}{$\mathrm{g} / \mathrm{ha} / \mathrm{dia}$} & \multirow[t]{2}{*}{$\mathrm{kg} / \mathrm{animal} / \mathrm{ano}$} & & \\
\hline & Chuvas & Seca & & Chuvas & Seca \\
\hline Pastagem arborizada & $570^{\mathrm{a}}$ & $428^{\mathrm{a}}$ & 179,6 & 1,8 & 1,2 \\
\hline Pastagem exclusiva de $B$. decumbens & $542^{\mathrm{a}}$ & $306^{\mathrm{b}}$ & 152,6 & 1,8 & 1,1 \\
\hline
\end{tabular}

${ }^{1}$ Medias seguidas por letras diferentes na mesma coluna diferem significativamente pelo teste Newman-Keuls. Alvim et al. (2005).

\section{Recria em semi confinamento}

Segundo Krug (2001) o sistema de semi confinamento é o mais usado para gado de melhor padrão genético. Esse sistema consiste em manter os animais no pasto, especialmente no período das águas, e suplementar com alimentação volumosa e concentrada no período da seca em regime de confinamento parcial, quando necessário. A alimentação volumosa e concentrada e feita em cochos, cobertos ou não, nas dependências das instalações, nas pastagens ou nos piquetes.

No sistema de semi confinamento, a recria das fêmeas pode seguir o mesmo esquema de manejo adotado para as vacas em lactação e vacas secas. Após a desmama ou desaleitamento das bezerras, até a fase de novilhas, estas poderão ser manejadas em piquetes ou pastagens, divididas em grupos ou lotes de animais de acordo com a idade ou peso, para evitar competição de alimentos no cocho.

\section{Recria em confinamento}

Vaz et al. (2012) no sistema de recria em confinamento, os alimentos são levados às novilhas que permanecem confinadas todo o tempo, sem acesso a pasto. Elas podem receber, no cocho, forrageira verde picada e/ou silagem e/ou feno. Estes autores também afirmam que o fornecimento de dietas a base de silagem de milho para novilhas, deve-se observar a necessidade de suplementação proteica, se não foi utilizada a ureia ou outra fonte de nitrogênio não proteico no momento da ensilagem. Às vezes, e necessário limitar o consumo da silagem para evitar que as novilhas fiquem obesas. Um feno de excelente qualidade e, sem dúvida, o melhor alimento para as novilhas mantidas sob confinamento. Ele pode constituir-se no único alimento para esta categoria animal. A mistura em partes iguais (na base da matéria seca) de feno e silagem de milho pode ser considerada como o melhor alimento para esta categoria animal, quando em confinamento.

Mendes Neto et al. (2007) avaliaram o efeito da substituição do feno de tifton85 (níveis 0; 16,$6 ; 33,3$ e $50 \%$ ) pela polpa cítrica sobre o consumo de nutrientes, a digestibilidade aparente dos nutrientes, o desempenho, o desenvolvimento ponderal, a conversão alimentar e a economicidade das dietas para novilhas leiteiras. 
Foi verificado que a conversão alimentar não foi afetada pelos níveis de substituição do feno pela polpa cítrica, sendo o valor médio de 6,99. Observou-se também, aumento linear no ganho de peso das novilhas à medida que o feno foi substituído pela polpa cítrica. O aumento no ganho de peso pode ser explicado pelo aumento linear no consumo de MS nos animais alimentados com maior nível de substituição do feno nas dietas. Houve um decréscimo na velocidade de crescimento dos animais com o aumento no nível de substituição do feno pela polpa cítrica.

Silva et al. (2006) avaliaram em seu estudo o desempenho de novilhas mestiças que receberam dietas com silagem de capim elefante aditivada com diferentes níveis de bagaço de mandioca (5, 10,15 e $20 \%$ na base da matéria natural) que seria um subproduto da industrialização da mandioca para a fabricação de polvilho, obtido após lavagens consecutivas da massa de mandioca. Segundo Silva et al. (2006), pode conter até $60 \%$ de amido, e constitui uma fonte de carboidrato rapidamente fermentável. Esses autores verificaram que o ganho médio diário de peso não diferiu entre os tratamentos, sendo a média de ganho igual a $1,07 \mathrm{~kg}$. Verificando, portanto, que o nível de adição de $5 \%$ de bagaço de mandioca a silagem de capim elefante é satisfatório, propiciando bom consumo e bom desempenho animal, não sendo necessária à adição de bagaço de mandioca em níveis mais elevados.

Nascimento et al. (2008) e Rêgo et al. (2010)afirmam que as silagens de milho, sorgo e o capim Napier picado podem ser utilizados como fontes alternativas de volumosos na seca. No entanto, esta última deve ser colhido com, no máximo 60 dias de idade e 1,30 a 1,60metros de altura, não se esquecendo de um correto balanceamento proteico da dieta.

Estes pesquisadores também afirmaram que, desta forma e de suma importância atentar para a qualidade dos volumosos fornecida as novilhas, pois à medida que as novilhas se desenvolvem $\mathrm{e}$ quantidades fixas de concentrado (2 $\mathrm{kg} /$ dia/novilhas) são fornecidas, o déficit nutricional em energia e proteína se eleva, o qual deverá ser completado pelos volumosos, comprovando a importância da qualidade das pastagens, capineiras, fenos e silagens na alimentação das novilhas.
Aspectos importantes ligados à alimentação de novilhas

Segundo Fernandes et al. (2004) para melhorar a eficiência reprodutiva, e de grande importância o melhoramento das técnicas de alimentação das novilhas, que servirão mais tarde para reposição das matrizes do rebanho. O ganho de peso desses animais não deve ser excessivo e dietas com níveis moderados em nutrientes parecem ser suficientes durante a fase de recria.

A superalimentação pode resultar em problemas reprodutivos futuros, ao proporcionar acúmulo de gordura ao redor dos ovários, prejudicando a irrigação sanguínea e também ao longo do canal de parição causando seu estreitamento, o que dificultaria o parto (Fernandes et al., 2004). A gordura em excesso também pode diminuir o desenvolvimento dos tecidos secretores do úbere, reduzindo, assim, a capacidade de produção de leite (Fernandes et al., 2004).

Fernandes et al. (2004) afirmam que a maturidade das novilhas é um processo gradual, sendo resultado de uma série de componentes endócrinos e fisiológicos, em que o tamanhoalvo, representado pelo peso a primeira monta, torna-se tão importante quanto a idade do animal.

O NRC (2001) baseado em trabalhos de Hoffman (1997), Van Amburgh et al. (1998) apud Schafhäuser Júnior (2006), além de outros, afirmam que ganhos de peso da ordem de 0,8 a $0,9 \mathrm{~kg} / \mathrm{dia}$ propiciam a ocorrência do primeiro parto antes dos 24 meses. Essas afirmações tem como meta o parto precoce, levando em consideração conclusões como as de Pirlo et al. (2000) e Van Amburgh et al. (1998) apud Schafhäuser Júnior (2006). O primeiro autor cita que a perda em produção de leite causada pela redução da idade ao primeiro parto de 29 para 23 meses, e compensada pelos menores custos da recria. O segundo autor observou que novilhas recriadas a uma taxa de ganho de peso de 0,94 $\mathrm{kg} /$ dia pariram pela primeira vez antes dos 24 meses de idade, mas produziram $5 \%$ menos leite do que o grupo com taxa de ganho de $0,68 \mathrm{~kg} / \mathrm{dia}$ (8.558vs. $9.008 \mathrm{~kg} / 305$ dias, LCG - leite corrigido gordura a 4\%), mas não houve diferença quando as produções foram corrigidas para peso ao parto.

\section{Exigências nutricionais de novilhas leiteiras}

Segundo Costa et al. (2007) em animais em crescimento, parte dos nutrientes consumidos é 
direcionada para atender as exigências de mantença e o restante, para desenvolvimento corporal, caracterizado por hiperplasia e hipertrofia celular. Desta forma, quando o consumo de MS aumenta, ocorre diluição das exigências de mantença. No passado, assumia-se que, para animais em crescimento, cada Mcal adicional de energia metabolizável (EM) consumida seria utilizado para aumento da massa tecidual. Entretanto, a relação entre consumo de EM e ganho de peso não é linear, pois a eficiência de conversão de EM para energia Liquida (EL) não é constante. Santos et al. (2002) afirmam que à medida que o animal cresce o "déficit" nutricional também aumenta, como consequência do fato de que a quantidade de concentrado oferecida a novilha e sempre constante. Assim sendo, o volumoso começa depois dos quatro meses de idade, a desempenhar um papel extremamente importante na nutrição das novilhas, sendo responsável pelo déficit nutricional calculado. Segundo Santos et al. (2001) a categoria de seis a doze meses, possui exigência nutricional um pouco menor do que animais com idade acima de doze meses e maior capacidade de consumo de matéria seca, porém não merece menor atenção, devendo-se oferecer alimentos em quantidade e qualidade necessária ao bom desenvolvimento da novilha. Segundo Pires et al. (2004), a exigência diária para uma novilha em crescimento com peso vivo de $250 \mathrm{~kg}$ e de 5,65 $\mathrm{kg}$ de MS, 3,7 $\mathrm{kg}$ de NDT e $678 \mathrm{~g}$ de proteína bruta.

Rabelo et al. (2007) afirmam que as exigências nutricionais de $\mathrm{Ca}, \mathrm{P}, \mathrm{Mg}$, $\mathrm{Na}$ e $\mathrm{K}$ não diferem entre as raças Guzerá e Holandesa para novilhas com peso vivo (PV) entre 200 e 300kg. A concentração corporal $(\mathrm{g} / \mathrm{kg}$ de peso de corpo vazio - PCVZ) e as exigências líquidas $(\mathrm{g} / \mathrm{kg}$ de ganho de PCVZ ou PV) de $\mathrm{Ca}, \mathrm{P}, \mathrm{Mg}$, Na e K diminuem à medida que o peso dos animais se eleva. As exigências líquidas, estimadas pela equação geral, para ganho de $1 \mathrm{~kg}$ de PCVZ, para novilhas das raças Guzerá e Holandesa com PV entre 200 e $300 \mathrm{~kg}$, variam de 11,57 a 9,59 g para o Ca; 5,97 a 4,94 g para o $\mathrm{P} ; 0,36$ a $0,31 \mathrm{~g}$ para o $\mathrm{Mg} ; 1,30$ a 1,23 para o $\mathrm{Na}$; e 0,86 a 0,77 para o K. As exigências dietéticas totais, estimadas pela equação geral, para ganho de $1 \mathrm{~kg}$ de $\mathrm{PV}$, para novilhas das raças Guzerá e Holandesa com PV entre 200 e $300 \mathrm{~kg}$, variam de 26,12 a $27,08 \mathrm{~g}$ para o Ca; 13,68 a 15,71 g para o $\mathrm{P} ; 5,29$ a $6,82 \mathrm{~g}$ para $\mathrm{p} \mathrm{Mg} ; 2,68$ a 3,36 g para o Na; e 21,16 a $30,77 \mathrm{~g}$ para o $\mathrm{K}$. As exigências nutricionais das novilhas cresce conforme a idade, o que pode ser observado no quadro 2, extraída do NRC (2001).

\section{Cana de açúcar na recria de novilhas leiteiras}

Capacidade de ingestão de cana de açúcar pelos bovinos

Pinto et al. (2009) afirmam que um animal alimentado à vontade só consegue ingerir quantidade limitada de cana de açúcar. O consumo está diretamente relacionado com o conteúdo de fibra (FDN). Quanto maior o teor de fibra da cana de açúcar e menor a digestibilidade da fração fibrosa, menor será o consumo deste volumoso, ou seja, a taxa de digestão da fibra da cana de açúcar no rúmen e muito baixa e o acúmulo de fibra não digerida no rúmen limita o consumo.

Galina et al. (2003), Pinto et al. (2009) verificaram baixa digestibilidade dos componentes fibrosos da cana de açúcar, embora o $\mathrm{pH}$ no líquido ruminal fosse adequado para a digestão da fibra. Por outro lado, tem sido demonstrado em trabalhos com cana de açúcar para bovinos que a fração de açúcares solúveis e que contribui com a maior parte da energia que o animal obtém deste alimento. Tendo em vista esses aspectos, torna-se importante conhecer a qualidade da cana de açúcar que será fornecida aos animais, em termos de conteúdo de fibra, conteúdo de açúcar e razão fibra: açúcar.

Segundo Galina et al. (2003) e Pinto et al. (2009) um dos fatores que limitam a utilização da cana de açúcar na alimentação de ruminantes é a baixa degradação da fibra no rúmen, o que leva a uma limitação da taxa de reciclagem ruminal, e, consequentemente, ao baixo consumo. Resultado semelhante foi observado Salinas-Chavira et al. (2013) ao mostrarem que a taxa de digestão da fibra da cana de açúcar no rúmen foi muito baixa e que o acumulo de fibra não digestível limitava o consumo. Assim sendo, a limitação mais importante reside no baixo consumo de cana de açúcar pelo animal e, por conseguinte, na reduzida ingestão de energia.

Entre os fatores que afetam a qualidade da cana de açúcar como alimento para bovinos, os mais importantes são a idade da planta e a variedade (Rodrigues et al., 1997). O efeito da idade da planta está bem estabelecido (Rodrigues et al., 1997). No entanto, o efeito de variedade é pouco estudado, considerando-se o desempenho por bovinos. 
Quadro 2. Consumo de matéria seca (CMS), exigências nutricionais de proteína bruta (PB), proteína degradável no rúmen (PDR), proteína não degradada no rúmen (PNDR), energia líquida de crescimento (ELC), nutrientes digestíveis totais (NDT), fibra em detergente ácido (FDA), fibra em detergente neutro (FDN), carboidratos não fibrosos (CNF), alguns minerais e vitaminas, na dieta de novilhas da raça Holandesa e Pardo Suíça em crescimento.

\begin{tabular}{lcccc}
\hline \multirow{2}{*}{ Nutrientes, base na MS } & \multicolumn{4}{c}{ Idade, meses } \\
\cline { 2 - 5 } CMS (\% do PV) & $3-6$ & $>6-12$ & $>12-18$ & $>18-24$ \\
\hline PB (\%) & $2,7-3,0$ & $2,6-2,8$ & $2,4-2,6$ & $1,9-2,1$ \\
PDR (\% da PB) & $15-16$ & $14-15$ & $13-14$ & $14,5-15,5$ \\
PNDR (\% da PB) & $75-80$ & $80-85$ & $95-100$ & $50-55$ \\
ELC (Mcal/Kg) & $20-25$ & $15-20$ & $0-5$ & $45-50$ \\
NDT (\%) & $1,06-1,26$ & $0,92-1,13$ & $0,78-0,89$ & $0,97-1,03$ \\
FDA (\%) & $68-74$ & $64-70$ & $60-63$ & $68-70$ \\
FDN (\%) & 20,0 & 22,0 & 24,0 & 25,0 \\
CNF (\%) & 32,0 & 30,0 & 32,0 & 35,0 \\
Cálcio (\%) & 35,0 & 30,0 & 25,0 & 34,0 \\
Fósforo (\%) & $0,50-0,60$ & $0,45-0,55$ & $0,40-0,50$ & $040-0,50$ \\
Magnésio (\%) & $0,35-0,40$ & $0,32-0,35$ & $0,28-0,32$ & $0,28-0,32$ \\
Potássio (\%) & $0,20-0,30$ & $0,20-0,30$ & $0,20-0,30$ & $0,20-0,30$ \\
Sódio (\%) & $0,65-0,80$ & $0,65-0,80$ & $0,65-0,80$ & $0,65-0,80$ \\
Cloro (\%) & 0,10 & 0,10 & 0,10 & 0,10 \\
Enxofre (\%) & $0,15-0,20$ & $0,15-0,20$ & $0,15-0,20$ & $0,15-0,20$ \\
Ferro (ppm) & $0,16-0,20$ & $0,16-0,20$ & $0,16-0,20$ & $0,16-0,20$ \\
Cobalto (ppm) & $20-40$ & $20-40$ & $20-40$ & $20-40$ \\
Cobre (ppm) & 0,10 & 0,10 & 0,10 & 0,10 \\
Manganês (ppm) & $10-16$ & $10-16$ & $10-16$ & $10-16$ \\
Zinco (ppm) & $20-24$ & $20-24$ & $20-24$ & $20-24$ \\
Iodo (ppm) & $25-70$ & $25-70$ & $25-70$ & $25-70$ \\
Selênio (ppm) & $0,3-0,4$ & $0,3-0,4$ & $0,3-0,4$ & $0,3-0,4$ \\
\hline Fontes: NRC & 0,30 & 0,30 & 0,30 \\
\hline & 0,30 & & \\
\hline
\end{tabular}

Fontes: NRC (2001)

Produtividade, Características e Composição Química da cana de açúcar.

A cana de açúcar foi trazida para o Brasil pelos primeiros colonizadores, sendo utilizada como recurso forrageiro na alimentação dos ruminantes (Azevêdo et al., 2003).

Segundo a CONAB - Companhia Nacional de Abastecimento (2015), a produção de cana de açúcar para a safra 2015/16 está estimada em 658,7 milhões de toneladas. O crescimento deverá ser de $3,8 \%$ em relação à safra anterior. A área plantada prevista deve ficar em 8.995,5 mil hectares, redução prevista de $0,1 \%$, se comparada com a safra 2014/15.

A cana de açúcar, como alimento básico para ruminantes, apresenta limitações de ordem nutricional, devido aos baixos teores de proteína, minerais e ao alto teor de fibra de baixa degradação ruminal (Maeda et al., 2011).

A produção e a composição químicobromatológica da cana de açúcar está representada no quadro 3.

Segundo Fernandes et al. (2003) para os teores de MS, não houve diferença quanto aos 
ciclos de produção (precoces e intermediarias) e para idade de corte. Os mesmos autores afirmam que, entretanto, ao primeiro corte (426 dias) o teor foi, em média, 9,5\% menor que ao segundo e terceiro cortes $(487$ e 549 dias, respectivamente). Esta diferença pode ser explicada pelo aumento da capacidade fotossintética das plantas e pela perda de umidade, principalmente nas folhas, que normalmente ocorre na época seca.

Quadro 3. Produção e composição químico-bromatológica para cana de açúcar, considerando os efeitos do ciclo de produção e idade de corte.

\begin{tabular}{lccccc}
\hline Itens & \multicolumn{2}{c}{ Ciclo de produção $^{1}$} & \multicolumn{3}{c}{ Idade corte (dias) } \\
& Precoce & Intermediária $^{2}$ & 426 & 487 & 549 \\
\hline MS, \% & 28,72 & 28,69 & 27,02 & 29,73 & 29,38 \\
NDT, \% & $62,47 \mathrm{~b}$ & $63,51 \mathrm{a}$ & 62,45 & 63,02 & 63,5 \\
MM, \% & $16,12 \mathrm{a}$ & $15,64 \mathrm{a}$ & 17,96 & 16,43 & 13,2 \\
FDN, \% & $487,56 \mathrm{a}$ & $471,03 \mathrm{~b}$ & 476,56 & 485,33 & 476 \\
LIG, \% & $13,46 \mathrm{a}$ & $13,36 \mathrm{a}$ & 14,25 & 12,85 & 13,13 \\
FDA, \% & $287,87 \mathrm{a}$ & $274,54 \mathrm{~b}$ & 267,19 & 293,11 & 283,31 \\
PIDN & $13,55 \mathrm{a}$ & $14,06 \mathrm{a}$ & 14,77 & 12,96 & 13,69 \\
PIDA & $2,91 \mathrm{a}$ & $2,94^{\mathrm{a}}$ & 3,05 & 2,81 & 2,9 \\
PSDN & $86,45 \mathrm{a}$ & $85,94 \mathrm{a}$ & 85,23 & 87,04 & 86,31 \\
Prod & $126,30 \mathrm{~B}$ & $137,24 \mathrm{~A}$ & 121,16 & 136,15 & 138,00 \\
\hline Adapt & & & &
\end{tabular}

Adaptado de Fernandes et al. (2003).

As variedades de cana de açúcar com ciclo de produção intermediário apresentaram valores de NDT (Nutrientes Digestíveis Totais) maiores do que os das variedades precoces, o que pode ser atribuído a sua menor concentração em FDA (Fibra em Detergente Acido), uma vez que a lignina se concentra na fração de FDA e consequentemente, esta variável tem sido altamente correlacionada com a digestibilidade (Mertens, 1987).

Fernandes et al. (2003) afirmam que as variedades de cana de açúcar de ciclo de produção intermediário apresentaram melhor valor nutricional que as precoces, caracterizadas pelos menores teores de FDN e FDA, menor repleção ruminal total e maior porcentagem de NDT e brix (teor de açúcar da cana de açúcar). O avanço da idade de corte acarretou redução da fibra potencialmente digestível, aumento da fração não degradável e da repleção ruminal total.

Moreira et al. (2004) afirmam que de maneira geral, o valor nutritivo das gramíneas diminui com o avançar do estádio de maturação. No entanto, o valor nutritivo da cana de açúcar aumenta com a maturidade. Segundo Andrade et al. (2004) com o avançar da idade da cana de açúcar ocorrem decréscimos nos teores de PB e aumento nos teores de MS e dos carboidratos não fibrosos (CNF), sendo este último resultado do acumulo de sacarose. Ocorre também queda na digestibilidade da FDN e aumento dos CNF, o que resulta em aumento na digestibilidade da matéria orgânica (DMO) com o avanço da idade da planta, o que representa uma importante vantagem para a alimentação animal, particularmente no período seco e frio do ano.

Fernandes et al. (2003) considerando intervalos de quatro meses entre cortes da cana, verificaram que as diferenças nos teores de FDN e FDA foram relativamente pequenas, o que evidencia a capacidade desse volumoso em manter constante o seu valor nutritivo ao longo do tempo, contrariamente ao que ocorre com a maioria das espécies forrageiras tropicais. Entretanto devido aos baixos teores de proteína e minerais da cana de açúcar, torna-se necessário a suplementação destes nutrientes em dietas com alta inclusão desta fonte volumosa, para que sejam atendidas as exigências dos animais. 
Formas de utilização da cana de açúcar para novilhas leiteiras

\section{Cana de açúcar in atura}

Segundo Pinto et al. (2003) o valor nutricional da cana de açúcar in natura está diretamente ligado ao seu teor de açúcar, que pode chegar a $50 \%$ na matéria seca, proporcionando valores de nutrientes digestíveis totais da ordem de $55 \%$ a $60 \%$; no entanto o seu teor de proteína e extremamente baixo, não ultrapassando $4 \%$, além do que essa proteína e de baixa digestibilidade. São também muito baixos os teores da maioria dos minerais, principalmente o fósforo. Entre os fatores que afetam a qualidade da cana de açúcar como alimento para ruminantes, os mais importantes são idade da planta e a variedade (Andrade et al., 2004).

\section{Cana de açúcar com ureia}

Reis et al. (2008) afirmam que o primeiro nutriente da cana de açúcar a ser corrigido e o nitrogênio, por ser um elemento essencial para o uso do seu alto potencial energético. A forma mais simples e barata de atender essa exigência e com a ureia mais uma fonte de enxofre. Ao alcançar o rúmen, a ureia libera amônia que combinada com os produtos da digestão do açúcar (os ácidos graxos voláteis) irão formar a proteína microbiana. De acordo com Andrade et al. (2001) a proteína bruta final da silagem decana acrescida de ureia $(9,4 \%$ na MS) foi menor, em seu experimento, que a cana in natura $(10,1 \%$ na MS), provavelmente pela percolação de nitrogênio, altamente solúvel nesta forma, porém os dois valores podem ser considerados muito bons.

Experimentos conduzidos pela Embrapa Gado de Leite com novilhos e ou novilhas em pastejo suplementados com cana de açúcar +ureia apresentaram ganho de peso vivo (GPV) em torno de 300g/animal/dia. Para maior ganho de peso, e necessário adicionar concentrado a dieta cana + ureia. OGPV da ordem de $800 \mathrm{~g} / \mathrm{animal} / \mathrm{dia}$ foi obtido, quando os animais recebendo a mistura cana + ureia foram suplementados com $1 \mathrm{~kg}$ de farelo de algodão/animal/dia. O ganho de peso vivo (GPV) superior a 500 g/animal/dia pode ser alcançado suplementando esta dieta com $1 \mathrm{~kg}$ de farelo de arroz/animal/dia (500 g/animal/dia) ou $1 \mathrm{~kg}$ de farelo de trigo/animal/dia (530g/animal/dia). No início do fornecimento de cana + ureia + fonte de enxofre, os animais devem passar por um período de adaptação (sete dias),quando se acrescenta $0,5 \%$ de ureia + fonte de enxofre diluído em 4 litros de água,na cana picada, apos este período passa a fornecer $1 \%$. Caso o fornecimento venha a ser interrompido por mais de um dia, os animais deverão ser novamente adaptados. Durante o fornecimento da cana + ureia manter sempre a disposição dos animais água e mistura mineral de boa qualidade, pois a cana de açúcar e deficiente em alguns minerais, como fósforo, cálcio, zinco e manganês.

\section{Silagem de cana de açúcar}

Segundo Pinto et al. (2003) a cana de açúcar pode ser conservada e utilizada na forma de silagem, diminuindo a necessidade de mão de obra adicional para o corte e a picagem diária desta forragem.

Pedroso (2003) afirma que a ensilagem de cana de açúcar tem sido realizada pelos pecuaristas, para facilitar o manejo da alimentação dos rebanhos e dos canaviais e também na ocorrência de incêndios e geadas para se evitar a perda da forragem. O inconveniente desta forrageira na obtenção de silagem e seu alto conteúdo de açúcares solúveis que resulta em rápida proliferação de leveduras com produção de etanol e gás carbônico (Pinto et al., 2003). Portanto, deve-se ter cuidado especial no processo de ensilagem, utilizando-se de preferência cana e outra forrageira picada no processo de enchimento do silo.

Segundo Pedroso (2003) a ensilagem de cana de açúcar sem o uso de aditivos (controle) resultou em perdas de $50 \%$ na concentração de carboidratos solúveis em água (CHOs) da forragem e de $5,4 \%$ da digestibilidade verdadeira in vitro da MS (DVIVMS). Para este mesmo pesquisador o desempenho de novilhas alimentadas com ração contendo silagem de cana sem aditivos, foi inferior em relação ao desempenho frequentemente observado para bovinos recebendo dietas contendo cana de açúcar fresca, como volumoso exclusivo, em proporções semelhantes ou maiores usados em seu trabalho.

\section{Cana de açúcar hidrolisada}

Dentre os alimentos volumosos utilizados para suplementação dos bovinos, a cana de açúcar e um dos mais acessíveis ao bolso do produtor. Contudo, a cana tem um ponto desfavorável, a baixa digestibilidade, que 
compromete o consumo, porque a cana tem em sua composição um alto teor de lignina. Este problema pode ser contornado por um processo chamado hidrolisação. Sendo a maneira mais prática e economicamente viável de hidrolisar a cana in natura e na propriedade, podendo ser com o uso de soda caustica (Hidróxido de Sódio) ou a Cal Virgem Micro pulverizada. Esta segunda substância tem eficiência $10 \%$ menor nos benefícios finais em relação ao hidróxido de sódio, porem tem imensas vantagens que compensam, tais como: tratamento pelo menos nove vezes mais econômico do que a soda, representa menor perigo aos funcionários. Faz-se necessário o uso de $1 \%$ de cal virgem na matéria verde da cana para que ocorra hidrolisarão eficiente. A cana hidrolisada apresenta as seguintes vantagens em relação à cana in natura:

1. Estocagem por 4 a 5 dias, liberando os funcionários de colher nos finais de semana;

2. Manutenção do $\mathrm{pH}$ por volta de 5,5 a 7,0, que evita sua fermentação, melhorando o aproveitamento no cocho;

3. Eliminação de ácido acético e do teor alcoólico da cana, que favorece sua ensilagem;

4. Controle da acidose nos animais; Eliminação de abelhas no cocho;

5. Melhora na digestibilidade palatabilidade, neste caso devido ao cheiro de melaço.

Segundo Silva et al. (2007) a cana hidrolisada deve ser fornecida aos animais com complemento proteico, que pode ser concentrado de farelo de soja, de algodão ou ureia, a fim de atender as necessidades nutricionais do animal.

\section{Bagaço de cana de açúcar}

Pires et al. (2004) em seu experimento avaliaram o valor nutritivo do bagaço de cana de açúcar tratado com amônia e, ou, sulfeto de sódio, verificando a conservação, a composição químico-bromatológica e o desempenho de novilhas Holandês vs. Indubrasil. Este bagaço proveniente de usinas de açúcar, álcool ou aguardente constitui um problema, por ser pouco utilizado, sendo muitas vezes queimado ao ar livre, enquanto poderia ser usado na alimentação de ruminantes. Foram utilizados 4 tratamentos sendo T1 - Bagaço sem tratamento (armazenado em local coberto), T2 - Bagaço tratado com 2,5\% de Na2S, T3 - Bagaço tratado com $4 \%$ de NH3 e
T4 - Bagaço tratado com $2,5 \%$ de $\mathrm{Na} 2 \mathrm{~S}+4 \%$ de NH3. Verificou-se efeito para ganho de peso diário e total, observaram-se maiores ganhos para os tratamentos com NH3. A conversão alimentar não foi influenciada pelos tratamentos, registrando-se valores de 7,26; 7,73; 6,69 e 6,33, respectivamente, para os tratamentos testemunha, $\mathrm{Na}_{2} \mathrm{~S}, \mathrm{NH}_{3}$ e $\mathrm{NH}_{3}$ mais $\mathrm{Na}_{2} \mathrm{~S}$. Obteve-se um resultado, que o fornecimento de bagaço de cana de açúcar tratado com amônia anidra proporciona maior ganho de peso para novilhas em crescimento, comparado ao fornecimento de bagaço sem tratamento.

Um dos efeitos da ação da amônia sobre a forragem e a desestruturação do complexo formado pelos componentes da fibra (celulose, hemicelulose e lignina), oferecendo aos microrganismos maior área de exposição e, consequentemente, aumentando o grau de utilização das diferentes frações da fibra. Outro efeito marcante da amonizacão e o incremento no teor dos compostos nitrogenados, que, normalmente, e baixo, o que limita o crescimento dos microrganismos do rúmen (Garcia \& Neiva, 1994 apud (Pires et al., 2004).

\section{Outras formas de utilização de cana de açúcar para novilhas leiteiras}

Andrade (1999) observou que a digestibilidade aparente da FDN no trato digestivo total de novilhas e vacas leiteiras, consumindo dietas formuladas com cana $\mathrm{e}$ concentrados a base de milho e farelo de soja, foi cerca de metade da digestibilidade da FDN de dietas com mesmo conteúdo de FDN oriundo de forragem formulada com silagem de milho e os mesmos concentrados.

Costa (2002) apud Melo (2003) encontrou valores de degradabilidade efetiva da FDN no rúmen semelhantes aos valores de digestibilidade aparente no trato total encontrado por $\underline{\text { Andrade }}$ (1999), evidenciando a importância dos eventos ruminais para a digestibilidade da fibra da cana de açúcar. Gallo (2001) observou tendência de queda linear no consumo de matéria seca de novilhas holandesas alimentadas com dietas de conteúdo crescente de FDN oriundo de cana. As dietas lipoproteicas continham 62, 70 e $78 \%$ de cana na matéria seca, correspondendo a 330, 380 e 420 gramas de FDN oriundo desta forrageira por quilo de matéria seca dietética respectivamente. Mesmo em dietas formuladas com baixa porcentagem de FDN na matéria seca, 
observou-se menor consumo de matéria seca como porcentagem do peso vivo $3,48 v$ s. $3,76 \%$ em vacas holandesas alimentadas com cana de açúcar comparativamente a silagem de milho (Dias et al., 2011). A limitação do consumo pode reduzir a ingestão de açúcar solúvel, que é a fração que contribui com a maior parte do fornecimento de energia ao animal. Baseado nisso, uma possível estratégia para utilização da cana na alimentação animal seria fornecer o material com tamanho de partícula reduzido, aumentando a taxa de passagem da fibra no rúmen sem prejudicar a utilização da sacarose.

Espinoza et al. (2006) apud Borges et al. (2008) trabalhando com novilhas cruzadas Holandês vs. Brahman avaliaram a suplementação ou não com cana de açúcar por três meses antes do parto. O tratamento 1 (T1) era composto de pasto mais $1,5 \mathrm{~kg} / \mathrm{cabeça/dia} \mathrm{de}$ concentrado e o tratamento 2 (T2) pelos mesmos ingredientes do $\mathrm{T} 1$ mais $4 \mathrm{~kg}$ de cana de açúcar/dia com a adição de $4 \%$ de ureia. A média de produção de leite por animal foi de 6 e $8 \mathrm{~L} /$ dia para T1 e T2, respectivamente, com produção por lactação superior em 28\% (1.269 para T1 e 1.634 litros para T2) para os animais que receberam cana de açúcar. Provavelmente as primíparas do T2 obtiveram maior produção de leite em consequência do maior ganho de peso desde o sétimo mês de gestação até o momento do parto (669 vs. $956 \mathrm{~g} / \mathrm{animal} / \mathrm{dia})$. A suplementação promoveu melhor condição corporal dos animais ao parto e diminuição do intervalo entre partos (454 vs. 347 dia).

Pereira (2003) trabalhando com novilhas Holandesas avaliou a utilização da cana de açúcar na alimentação desses animais. Foram realizados dois trabalhos sendo que no primeiro usaram dietas contendo $320 \mathrm{~g}$ de FDN oriundo de cana de açúcar ou a mesma quantidade de FDN oriundo de silagem de milho por kg de matéria seca dietética. Neste caso, a silagem de milho foi utilizada como controle para comparação, já que e a forrageira predominante nas fazendas brasileiras trabalhando com bovinos da raça holandesa. Segundo esse pesquisador o ganho de peso foi superior nos tratamentos com silagem de milho (1175 vs. 1009 g). As dietas com cana tenderam a reduzir o consumo diário de matéria seca $(8,2$ vs. $8,7 \mathrm{~kg})$. A menor digestibilidade da FDN nas dietas com cana $(22,5 \%$ vs. $43,7 \%)$ foi compensada pela maior digestibilidade da matéria orgânica não-fibrosa $(87,6 \%$ vs. 78,65$)$, refletindo a alta digestibilidade da sacarose comparativamente ao amido da silagem de milho.

O segundo trabalho foi conduzido para determinar o nível máximo permitido de cana na dieta de novilhas Holandesas. O consumo diário de MS caiu linearmente com a maior inclusão de cana na dieta $(7,4$ vs. 6,8 vs. $6,6 \mathrm{~kg}$ nas dietas contendo 62,70 e $78 \%$ de cana). O ganho diário de peso foi 1002, 979 e $951 \mathrm{~g}$, apresentando tendência em queda similar ao consumo.

\section{Considerações finais}

Observando as formas de utilização da cana de açúcar para novilhas pode-se concluir que quando usada na forma in natura não supre as necessidades nutricionais das novilhas por sua baixa digestibilidade e teor proteico, o que tornaria necessário a suplementação com outros alimentos. Já a cana fornecida enriquecida com ureia teve bons resultados de ganho de peso para novilhas quando acrescido algum tipo de concentrado. A cana de açúcar fornecida como silagem deve ser utilizada quando adicionado junto à silagem algum tipo de aditivo, pois sem aditivo a silagem tem uma perda de 50\% na concentração de carboidratos solúveis.

$\mathrm{Na}$ forma hidrolisada supre as necessidades nutricionais dos animais desde que fornecida com algum concentrado. E na forma de bagaço a cana proporciona um bom ganho de peso quando tratado com amônia anidra. Apesar da baixa digestibilidade da cana de açúcar e do menor ganho de peso das novilhas quando comparadas com outros tipos de alimentações como, por exemplo, a silagem de milho, a cana de açúcar mostrou-se ser uma alternativa viável para recria de novilhas leiteiras.

O produtor deve optar pela forma de utilização da cana de açúcar que melhor seja adequado ao seu sistema de produção de leite. Levando em consideração que quanto mais tempo as novilhas ficarem sem produzir leite, maior será o custo desses animais.

\section{Referências Bibliográficas}

Abreu, C. L. (2012). Estratégias para utilização da cana de açúcar na alimentação de novilhas leiteiras: relações entre ureia, proteína verdadeira e amido. Departamento de Zootecnia. Universidade Federal de Viçosa, Viçosa. 
Alvim, M., Paciullo, D., Carvalho, M., Aroeira, L., Carvalho, L., Novaes, L., Gomes, A., Miranda, J. \& Ribeiro, C. (2005). Sistema de produção de leite com recria de novilhas em sistemas silvipastoris. EMBRAPA GADO DE LEITE, 1, 1-10.

Andrade, J. B., Ferrari Júnior, E., Possenti, R. A., Otsuki, I. P., Zimback, L. \& Landell, M. G. A. (2004). Composição química de genótipos de cana de açúcar rm duas idades, para fins de nutrição animal. Bragantia, 63, 341-349.

Andrade, J. B., Júnior, E. F., Possenti, R. A., Leinz, F. F., Bianchini, D. \& Carvalho, C. F. R. (2001). Valor nutritivo da cana de açúcar na forma de silagem ou" in natura". Boletim de Indústria Animal, 58, 135-143.

Andrade, M. A. F. (1999). Desempenho de novilhas holandesas alimentadas com cana de açúcar como volumoso único. Departamento de Zootecnia. Universidade Federal de Lavras, Lavras.

Aroeira, L. J. M., Paciullo, D. S. C., Macedo, R. \& Alvin, M. J. (2004). Sistema Silvipastoril para recria de novilhas leiteiras: aspectosmorfofisiológicos, produtivos e qualitativos. Embrapa Gado de Leite, 1, 36.

Azevêdo, J. A. G., Pereira, J. C., Carneiro, P. C. S., Queiroz, A., Barbosa, M. H. P., Fernandes, A. M. \& Rennó, F. P. (2003). Avaliação da divergência nutricional de variedades de cana de açúcar (Saccharum spp.). Revista Brasileira de Zootecnia, 32, 1431-1442.

Borges, A. L. C. C., Campos, M. M. \& Reis, S. R. (2008). Cana de açúcar na alimentação de bovinos. Revista Veterinária e Zootecnia em Minas, 1/2/3, 1-4.

Costa, M. G., Campos, J. M. S., Valadares Filho, S. C., Valadares, R. F. D., Mendonça, S. S., Souza, D. P. \& Teixeira, M. P. (2005). Desempenho produtivo de vacas leiteiras alimentadas com diferentes proporções de cana de açúcar e concentrado ou silagem de milho na dieta. Revista Brasileira de Zootecnia, 34, 2437-2445.

Costa, P. B., Queiroz, A. C., Rodrigues, M. T., Magalhães, L. R., Costa, M. G., Toral, F. L. B., Carvalho, T. A., Monteiro, L., Zorzi, K. \& Duarte, M. S. (2007). Desempenho de novilhas leiteiras sob manejo para crescimento compensatório recebendo suplementação com ionóforo. Revista Braseleira de Zootecnia, 36, 461-470.

Dias, A. M., Ítavo, L. C. V., Damasceno, J. C., Santos, G. T., Ítavo, C. C. B. F., da Silva, F. F., Nogueira, E. \& Soares, C. M. (2011). Sugar cane treated with calcium hydroxide in diet for cattle: Intake, digestibility of nutrients and ingestive behaviour. Revista Brasileira de Zootecnia, 40, 1799-1806.

Fernandes, A. M., Queiroz, A. C., Pereira, J. C., Lana, R. P., Barbosa, M., Fonseca, D. M., Detmann, E., Cabral, L. S., Pereira, E. S. \& Vittori, A. (2003). Composição químicobromatológica de variedades de cana de açúcar (Saccharum spp L.) com diferentes ciclos de produção (precoce e intermediário) em três idades de corte. Revista Brasileira de Zootecnia, 32, 977-985.

Fernandes, A. R. M., Sampaio, A. A. M., Cerqueira, A. A., Brito, R. M. \& Miguez, P. H. P. (2004). Recria de bezerras Canchim alimentadas com dietas contendo cana de açúcar e diferentes relações PDR: NDT. Ars Veterinária, 20, 256-265.

França, A. F. S., Mello, S. Q. S., Rosa, B., Reyes, B. A., Mundim, S. P., Maghalães, M. R. F., Matos, T. R. A. \& Reis, J. G. (2005). Avaliação do potencial produtivo e das características químico-bromatológicas de nove variedades de cana de açúcar irrigada. Livestock Research for Rural Development, 17.

Galina, M. A., Pérez-Gil, F., Ortiz, R. M. A., Hummel, J. D. \& Ørskov, R. E. (2003). Effect of slow release urea supplementation on fattening of steers fed sugar cane tops (Saccharum officinarum) and maize (Zea mays): ruminal fermentation, feed intake and digestibility. Livestock Production Science, $83,1-11$.

Gallo, P. C. S. (2001). Desempenho de novilhas holandesas alimentadas com teores dietéticos crescentes de cana de açúcar. Animal Science. Universidade Federal de Lavras., Lavras.

Krug, E. E. B. (2001). Estudo para identificação de benchmarking em sistemas de produção de leite no Rio Grande do Sul. Animal Science. Universidade Federal do Rio Grande do Sul, Porto Alegre.

Maeda, E. M., Zeoula, L. M., Jobim, C. C., Bertaglia, F., Jonker, R. C., Geron, L. J. V. \& 
Henrique, D. S. (2011). Chemical composition, fermentation, in vitro digestibility and in situ degradability of sugar cane silages with Lactobacillus, urea and agricultural byproduct. Revista Brasileira de Zootecnia, 40, 2866-2877.

Mendes Neto, J., Campos, J. M. S., Valadares Filho, S. C., Lana, R. P., Queiroz, A. C. \& Euclydes, R. F. (2007). Consumo, digestibilidade, desempenho, desenvolvimento ponderal e economicidade de dietas com polpa cítrica em substituição ao feno de capim-tifton 85 para novilhas leiteiras. Revista Brasileira de Zootecnia, 36, 626-634.

Mertens, D. R. (1987). Predicting intake and digestibility using mathematical models of ruminal function. Journal of Animal Science, 64, 1548-1558.

Moreira, F. B., Prado, I. N., Cecato, U., Wada, F. Y. \& Mizubuti, I. Y. (2004). Forage evaluation, chemical composition, and in vitro digestibility of continuously grazed star grass. Animal Feed Science and Technology, 113, 239-249.

Nascimento, W. G., Prado, I. N., Jobim, C. C., Emile, J. C., Surault, F. \& Huyghe, C. (2008). Valor alimentício das silagens de milho e de sorgo e sua influência no desempenho de vacas leiteiras. Revista Brasileira de Zootecnia, 37, 896-904.

NRC. (2001). Nutrient Requirements of Dairy Cattle, 7th rev. edn. Natl. Acad. Press, Washington, DC.

Pedroso, A. F. 2003. Aditivos químicos e microbianos no controle de perdas e na qualidade de silagem de cana de açúcar (Saccharum officinarum L.). Animal Science. Universidade de São Paulo, Piraicaba.

Pereira, M. N., Cana para boas vacas e novilhas. Revista Balde Branco, p.50-53, v. $38, \mathrm{n}^{\circ} 460$, Fevereiro/2003. (2003). Cana para boas vacas e novilhas. Revista Balde Branco, 38, 50-53.

Pinto, A. P., Nascimento, W. G., Abrahão, J. J. S., Perotto, D., Moletta, J. L. \& Lugão, S. M. B. (2009). Digestibilidade, consumo, desempenho e características de carcaça de tourinhos mestiços confinados com cana de açúcar ou silagem de sorgo. Revista Brasileira de Zootecnia, 38, 2258-2263.

Pinto, A. P., Pereira, E. S. \& Mizubuti, I. Y. (2003). Características nutricionais e formas de utilização da cana de açúcar na alimentação de ruminantes. Semina: Ciências Agrárias, 24, 73-84.

Pires, A. J. V., Garcia, R., Valadares Filho, S. C., Pereira, O. G., Cecon, P. R., Silva, F. F., Silva, P. A. \& Veloso, C. M. (2004). Novilhas alimentadas com bagaço de cana de açúcar tratado com amônia anidra e, ou, sulfeto de sódio. Revista Brasileira de Zootecnia, 33, 1078-1085.

Prado, I. N., Moreira, F. B., Cecato, U., Wada, F. Y., Oliveira, E. \& Rego, F. C. A. (2003). Sistemas para crescimento e terminação de bovinos de corte a pasto: avaliação do desempenho animal e características da forragem. Revista Brasileira de Zootecnia, 32, 955-965.

Rabelo, L. S., Borges, A. L. C., Gonçalves, L. C., Machado, G. S., Delgado, L. P., Ferreira, J. J., Borges, I., Rodriguez, N. M., Graça, D. S. \& Saliba, E. O. (2007). Composição corporal e exigências nutricionais de macrominerais para novilhas em crescimento das raças Guzerá e Holandesa. Arquivo Brasileiro de Medicina Veterinaria e Zootecnia, 59, 395-405.

Rêgo, M. M. T., Neiva, J. N. M., Rêgo, A. C., Cândido, M. J. D., Clementino, R. H. \& Restle, J. (2010). Nutritional evaluation of elephant-grass silages with byproduct of annato. Revista Brasileira de Zootecnia, 39, 2281-2287.

Reis, J. A. G., Reis, W., Paulo, V. \& Macedo, M. M. d. S. (2008). Diferentes níveis de uréia adicionados à cana de açúcar (Saccharum officinarum L.) no momento de sua hidrólise alcalina. Pubvet: Publicações em Medicina Veterinária e Zootecnia, 2, 1-6.

Ribeiro, M. D., Pereira, J. C., Vieira, R. A. M., Pacheco, B. M. \& Paula Leonel, F. (2005). Consumo e desempenho de novilhas em pastagem recebendo suplementos com diferentes níveis de proteína não degradável no rúmen. Revista Braseleira de Zootecnia, 34, 2486-2495.

Rodrigues, A. A., Primavesi, O. \& Esteves, S. N. (1997). Efeito da qualidade de variedades de cana de açúcar sobre seu valor como alimento para bovinos. Pesquisa Agropecuária Brasileira, 32, 1333-1338.

Salinas-Chavira, J., Almaguer, L. J., AguileraAceves, C. E., Zinn, R. A., Mellado, M. \& 
Ruiz-Barrera, O. (2013). Effect of substitution of sorghum stover with sugarcane top silage on ruminal dry matter degradability of diets and growth performance of feedlot hair lambs. Small Ruminant Research, 112, 73-77.

Santos, G. T., Cavalieri, F. L. B. \& Massuda, E. M. (2001). Alguns aspectos econômicos e de manejo na criação de novilhas leiteiras. Revista Balde Branco, 37, 56-60.

Santos, G. T., Damasceno, J. C., Massuda, E. M. \& Cavalieri, F. L. B. (2002). Importância do manejo e considerações econômicas na criação de bezerras e novilhas. Anais do II Sul - Leite: Simpósio sobre Sustentabilidade da PecuáriaLeiteira na Região Sul do Brasil. Santos, G.T., Maringá.

Schafhäuser Júnior, J. (2006). Desenvolvimento da glândula mamária durante a recria e sua influência no potencial produtivo de fêmeas leiteiras. Revista da FZVA, 13, 128-148.

Silva, D. A., Fernandes, A. R. M., Caldeirão, E. \& Carabolante, A. (2007). Digestibilidade da cana de açúcar hidrolisada, in natura e ensilada para bovinos. Ciência Animal Brasileira, 8, 41-50.

Silva, F. F., Aguiar, M. S. M. A., Veloso, C. M., Pires, A. J. V., Bonomo, P., Dutra, G. S., Almeida, V. S., Carvalho, G. G. P., Silva, R. R., Dias, A. M. \& Ítavo, L. C. V. (2006). Desempenho de novilhas leiteiras alimentadas com silagem de capim-elefante com adição de diferentes níveis de bagaço de mandioca. Arquivo Brasileiro de Medicina Veterinaria e Zootecnia, 58, 205-211.

Teixeira, R. M. A., Campos, J. M. S., Valadares Filho, S. C., Oliveira, A. S., Assis, A. J. \& Pina, D. S. (2007). Consumo, digestibilidade e desempenho de novilhas alimentadas com casca de café em substituição à silagem de milho. Revista Brasileira de Zootecnia, 36, 968-977.

Vaz, R. Z., Restle, J., Vaz, M. B., Pascoal, L. L., Vaz, F. N., Brondani, I. L., Filho, D. C. A. \& Neiva, J. N. M. (2012). Performance of beef heifers until calving receiving different levels of supplementation during the breeding season, at 14 months of age. Revista Brasileira de Zootecnia, 41, 797-806.

\section{Article History}

Received 17 July 2016

Accepted 10 August 2016

Available on line 1 September 2016

License information: This is an open-access article distributed under the terms of the Creative Commons Attribution License, which permits unrestricted use, distribution, and reproduction in any medium, provided the original work is properly cited. 